\title{
Parental Physical IIInesses and Their Association with Subsequent Externalizing and Internalizing Symptoms in Children
}

\author{
Lotta Kinnunen $\mathbb{1}^{1,2} \cdot$ Tanja Nordström $\mathbb{1}^{1,2} \cdot$ Mika Niemelä $^{3} \cdot$ Sami Räsänen ${ }^{3} \cdot$ Sarah Whittle $\mathbb{C}^{4} \cdot$ \\ Jouko Miettunen $\mathbb{D}^{1,2}$
}

Accepted: 12 August 2021 / Published online: 28 August 2021

(c) The Author(s) 2021

\begin{abstract}
Parental physical illnesses can be stressful for children. We estimated the prevalence of children who experience parental physical illnesses, and whether parental physical illnesses during childhood were associated with behavioral problems in adolescence. Data on children from the Northern Finland Birth Cohort 1986 was collected through questionnaires at ages 8 and $16(n=7037)$. Data on parental illness diagnosed during this study period was obtained from health registers. We investigated the association between parental physical illness (based on the International Classification of Diseases) and children's behavioral problems at age 16 (measured by the Youth Self-Report questionnaire). During the study period, 3887 $(55.2 \%)$ children had a parent with at least one physical illness. Associations were found between parental physical illness and children's behavioral problems, with most associations found between maternal illness and males' externalizing problems, and females' internalizing problems. After adjusting for child behavioral problems at age 8, parental psychiatric illness and socioeconomic status, and multiple testing correction, only associations between parental physical illness and male behavioral problems were significant. Interestingly, parental illness was associated with lower problems. A notable proportion of children experience parental physical illnesses. Although mixed, our findings suggest that the impact of parental physical illness on children's behavioral problems is complex, and that the experience of parental illness may lead to resilience in males. This study emphasizes that children's needs should be taken into account when treating a parent with physical illness.
\end{abstract}

Keywords Parental somatic illness $\cdot$ Children $\cdot$ Behavioral problems $\cdot$ Externalizing problems $\cdot$ Internalizing problems

\section{Highlights}

- Parental physical illnesses, diagnosed in specialized inpatient or outpatient care, are present for a substantial proportion of the population.

- Parental physical illnesses have an effect on children's mental health. However, this impact is complex with some negative and some positive effects on children.

- Male children may cope better than expected with some parental illnesses, and experiencing parental illness may lead to resilience among some male children.

Supplementary information The online version contains supplementary material available at https://doi.org/10.1007/s10826021-02079-y.

Lotta Kinnunen

lotta.kinnunen@student.oulu.fi

1 Center for Life Course Health Research, University of Oulu, P.O. Box 5000, Oulu 90014, Finland

2 Medical Research Center Oulu, Oulu University Hospital and University of Oulu, Medical Faculty, University of Oulu, P.O. Box 5000, Oulu 90014, Finland
Physical illnesses are defined as all illnesses other than mental illnesses and include (among others) cancer, circulatory, respiratory, digestive, skin and musculoskeletal

3 Department of Psychiatry, Oulu University Hospital, University of Oulu, P.O.Box 5000, Oulu 90014, Finland

4 Melbourne Neuropsychiatry Center, University of Melbourne, Level 3, Alan Gilbert Building, 161 Barry Street, Carlton, Victoria 3053, Australia 
diseases (World Health Organization [WHO], 1992). The burden of adult physical illnesses varies across regions, with illnesses such as circulatory diseases, diabetes, cancer and respiratory diseases associated with particular burden in developed countries, while the proportion of burden from communicable diseases is larger in developing countries (Vos et al., 2016). Physical illness in parents can be stressful for children, impacting both mental and physical health and development (Chen, 2017; Compas et al., 1994; Korneluk \& Lee, 1998; Pedersen \& Revenson, 2005; Sieh et al., 2010; Stoeckel \& Weissbrod, 2015). It is estimated that $4-12 \%$ of children may live with a seriously ill parent (Barkmann et al., 2007; Worsham et al., 1997). However, comprehensive prevalence data on different parental physical illnesses is scarce and the exact proportion of children affected by parental physical illnesses is unknown.

Children of a parent with a physical illness have been found to be at an increased risk for emotional and behavioral problems as well as adjustment difficulties (Chen, 2017; Houck et al., 2007; Sieh et al., 2010). Risk appears to be higher for internalizing as opposed to externalizing problems (Sieh et al., 2010). An expanding body of evidence implicates psychological and environmental mechanisms in explaining the association between parental physical illness and adverse child outcomes (Chen, 2017; Sieh et al., 2010). Parental physical illnesses may have various effects on family life, for example on relationships, communication and socioeconomic situation (Sieh et al., 2010), which may burden children. Parental physical illness can compromise a parent's ability to care for children through economic difficulties, disabilities or lack of physical, mental or social resources.

In contrast, some studies suggest that children of physically ill parents do better than expected, and parental illness may not necessarily have an adverse effect on children's mental health. For example, a longitudinal study involving parental cancer and children $(n=123)$ found that as the time passed, behavioral and emotional problems decreased and children reported fewer problems than a control group (Visser et al., 2007). Hoke (2001) found that children of parents with breast cancer $(n=35)$ were functioning better than children in a control sample after one year of diagnosis. In a Canadian population-based cohort study $(n=3771)$, maternal multiple sclerosis $(n=543)$ was found to be associated with higher social competence among five-year old children (Razaz et al., 2016). It is possible that these findings reflect the fact that certain individuals respond to negative events by experiencing positive emotions, such as optimism, hope and gratitude (Fredrickson et al., 2003; Nolen-Hoeksema \& Davis, 2002; Stoeckel et al., 2015).

Some studies have suggested that the gender of the child and the ill parent may moderate the association of parental illness and child psychological functioning (Compas et al.,
1994; Grant \& Compas, 1995; Sieh et al., 2010). Previous studies have indicated that maternal illness may have more adverse effects on children than paternal illness (Compas et al., 1994; Connell \& Goodman, 2002), possibly due to a larger amount of caregiving responsibilities (Grant \& Compas, 1995). Further, girls may be more prone to the influence of parental illness than boys (Compas et al., 1994; Korneluk \& Lee, 1998; Sieh et al., 2012). Girls exposed to parental illness have also been reported to display more internalizing problems and fewer externalizing problems than boys (Sieh et al., 2010). In contrast, some studies have found that neither the gender of the child nor of the ill parent is a significant factor in the association between parental illness and children's mental health (Dean et al., 2018; Lindqvist et al., 2007; Sieh et al., 2010).

Despite the cited research finding associations between parental physical illness and children's psychological symptoms, the number of studies are limited and the findings are inconsistent (e.g., Chen, 2017; Sieh et al., 2010; Umberger, 2014). As above, children affected by parental physical illness have been found to display various adjustment difficulties. On the other hand, some studies suggest that parental illness may have positive impacts on children's mental health (Hoke, 2001; Razaz et al., 2016), while other studies find null associations (Jantzer et al., 2013). Some of these inconsistencies may be due to relatively small and/or selected samples. While some studies report gender differences, most studies are limited by including only one parent (mainly the mother), whereas the effects of paternal physical illnesses have been studied less frequently. Further, findings are rarely based on longitudinal data, which is required for understanding the directional nature of associations. Comparative studies with symptoms in children of healthy parents are rare, and studies typically ignore the children's symptoms prior to the parental illness.

Furthermore, previous research has focused on specific illnesses and particularly serious life-threatening illnesses, such as parental cancer and HIV (Grabiak et al., 2007; Krattenmacher et al., 2012; Möller et al., 2014; Osborn, 2007; Tompkins \& Wyatt, 2008; Zhao et al., 2010), or parental chronic illnesses (Sieh et al., 2010). Thus, the overall picture of the impact of different parental physical illnesses on children's psychological symptoms is still unclear. Previous studies have suggested that the effect of parental illness on children's psychological functioning needs to be examined in different dimensions, such as parental illness characteristics (Chen, 2017). Yet, there is only one study that has systematically screened all parental illness categories (Merikukka et al., 2020), although this study focused on offspring mental disorders and use of psychotropic medication.

As such, considering the possible high prevalence of parental physical illnesses among the population of families 
with children, more research in this field is needed. This study aims to fill the identified gaps in the literature by examining the associations between different maternal and paternal physical illness groups and children's behavioral problems in a longitudinal study setting. The first aim of our study was to estimate the proportion of offspring affected by different parental physical illness groups according to the International Classification of Diseases (ICD) physical illness categories (WHO, 1992) during offspring's childhood (ages 8-16) in Northern Finland. In this study, parental physical illnesses are severe enough to require specialist referral, but were diagnosed via inpatient or outpatient care (i.e., they may or may not have required hospitalization). The second aim of our study was to investigate the association between various maternal and paternal physical illness groups during offspring's childhood and later behavioral problems among male and female offspring in adolescence. Although some research suggests that behavioral problems are more prominent in younger children (versus adolescent children) of chronically ill parents (Sieh et al., 2010), other research suggests that adolescent offspring of ill parents are at particularly high risk for mental health problems (Compas et al., 1994; Grant \& Compas, 1995; Welch et al., 1996). This may be because adolescents are more likely to be faced with increased family responsibilities that may be stressful (Grant \& Compas, 1995). As such, we focused on adolescent behavioral outcomes, and took into account important confounding factors including child behavioral problems prior to the onset of parental physical illness, socioeconomic status and parental psychiatric illness. Socioeconomic difficulties and parental mental health problems may explain part of the association between parental physical illness and child outcomes as low socioeconomic status of the family has been linked with adverse psychological outcomes of the offspring in earlier studies (Amone-P'Olak et al., 2009; Najman et al., 2010). Parental psychiatric disorders are associated with parental somatic illnesses (De Hert et al., 2011), and also with an increased risk of psychological symptoms and psychiatric disorders among offspring (Barnes \& Stein, 2000; Gladstone et al., 2011).

Based on previous literature, we hypothesized that adolescents with a parental physical illness would have higher levels of behavioral problems than adolescents without an affected parent. All analyses were stratified by gender of a parent and a child. We hypothesized that there would be gender-specific associations, such that female children's behavioral problems would be more pronounced (Compas et al., 1994; Sieh et al., 2012), particularly of ill mothers. Finally, we investigated all parental diagnosis groups separately rather than focus on a specific parental diagnosis or parental physical illness as one entity. Studying multiple parental diagnosis groups separately may allow for the identification of specific associations that may have been obscured in previous research. Identifying speficic parental diagnoses as risk factors for poor child mental health may help clinicians to better target preventive interventions on a focused group. Accordingly, the aim was to investigate which parental physical illness groups are associated with later behavioral problems in the adolescents.

\section{Methods}

This study is a prospective longitudinal cohort study including register and questionnaire data from the Northern Finland Birth Cohort 1986 (NFBC1986). The exposure is parental physical illness diagnosed in specialized in- or outpatient care when their children were between 8 and 16 years of age and the outcomes are children's Youth SelfReport (YSR) scores in adolescence (age 16) controlling for child behavioral problems prior to the onset of parental physical illness (age eight).

\section{Sample}

The NFBC1986 covers $99 \%$ of all of the children (9479 in total) born in Northern Finland during a one-year period (expected dates of birth between 1 July 1985 and 30 June 1986). The current analyses used data collected during childhood at age eight (in 1994), and adolescence at age 16 (in 2002). The questionnaires were approved by the Ethical Committee of the Northern Ostrobothnia Hospital District. Parental illness diagnostic data during the period when children were aged 8-16 was collected from nationwide health registers, that is there were no missing data. The final study population, who remained in the study until age 16, included a total of 7037 cohort members (74.2\%), of which 3655 were females $(51.9 \%)$ and 3382 males $(48.1 \%)$. Sample demographics and descriptives are presented in Table 1. Attrition was either due to death of the participant, missing address, insufficient or no anwers to questionnaires or refusal to use data. Attrition and participation rates in each phase are presented in Supplemental Fig. 1. More details about the NFBC1986 and questionnaires used in the study are available elsewhere (Miettunen et al., 2019).

\section{Rutter Children's Behavior Questionnaire at Age 8 Years}

When the cohort members were eight years old, their teachers completed a Rutter Children's Behavior Questionnaire scale B2 (Rutter-B; Rutter, 1967). Parents forwarded the questionnaire to the teachers and gave them permission to fill out the questionnaire. Rutter-B is a 26item questionnaire for evaluating behavioral problems. 
Table 1 Sample demographics and descriptives

\begin{tabular}{|c|c|c|c|c|}
\hline & $\begin{array}{l}\text { Total } \\
n=9479 \\
n(\%)\end{array}$ & $\begin{array}{l}\text { Study sample (YSR) } \\
n=7037 \\
n(\%)\end{array}$ & $\begin{array}{l}\text { Excluded } \\
n=2442 \\
n(\%)\end{array}$ & $p$-value \\
\hline \multicolumn{5}{|l|}{ Gender } \\
\hline Male & $4891(51.6)$ & $3382(48.1)$ & $1509(61.8)$ & $<0.001$ \\
\hline Female & $4587(48.4)$ & $3655(51.9)$ & $932(38.2)$ & \\
\hline \multicolumn{5}{|l|}{ SES } \\
\hline Entrepreneur or professional & $1629(19.9)$ & $1294(20.6)$ & $335(17.4)$ & $<0.001$ \\
\hline Skilled nonmanual & $1974(24.1)$ & $1609(25.6)$ & $365(19.0)$ & \\
\hline Unskilled, skilled manual or student & $4080(49.7)$ & $2973(47.3)$ & $1107(57.6)$ & \\
\hline Farmer & $519(6.3)$ & $404(6.4)$ & $115(6.0)$ & \\
\hline \multicolumn{5}{|l|}{ Residency } \\
\hline Urban & $4074(43.3)$ & $2970(42.5)$ & $1104(45.8)$ & 0.005 \\
\hline Rural & $5334(56.7)$ & $4025(57.5)$ & $1309(54.2)$ & \\
\hline Mother's age mean $(S D)$ & $28.3(5.5)$ & $28.5(5.5)$ & $27.7(5.6)$ & $<0.001$ \\
\hline Father's age mean $(S D)$ & $30.7(6.0)$ & $30.8(5.9)$ & $30.3(6.2)$ & $<0.001$ \\
\hline Parental psychiatric diagnosis & $2667(28.1)$ & $1966(27.9)$ & $701(28.7)$ & 0.467 \\
\hline Participation of Rutter-B & $8525(89.9)$ & $6521(92.7)$ & $2004(82.1)$ & $<0.001$ \\
\hline Rutter-B sum mean (SD) & $3.85(5.1)$ & $3.55(4.8)$ & $4.8(5.7)$ & $<0.001$ \\
\hline High $\geq 9$ & $1213(12.8)$ & $838(11.9)$ & $375(15.4)$ & $<0.001$ \\
\hline Low $<9$ & $7253(76.5)$ & $5639(80.1)$ & $1614(66.1)$ & \\
\hline No participation & $1013(10.7)$ & $560(8.0)$ & $453(18.6)$ & \\
\hline
\end{tabular}

Abbreviation: Rutter-B Rutter children's behavior questionnaire scale B2, SES socioeconomic status, $S D$ standard deviation, YSR Youth self-report
Items are rated on a scale of 0 to 2 , with higher ratings indicating more severe presence of symptoms. A total score of nine or more indicates a potential psychiatric disturbance (Rutter, 1967). Behavioral problems were calculated as the sum of Rutter-B items present at age eight. The Finnish version of the Rutter scale has been shown to be reliable and valid for research purposes (Kresanov et al., 1998). The reliability evaluation of Rutter-B in NFBC1986 was good as indicated by Cronbach's alpha (0.88).

\section{Youth Self-Report at Age 16 Years}

The Youth Self-Report (YSR) is a self-report assessment tool for evaluating the social competencies and behavioral problems of 11-18-year-old adolescents (Achenbach, 1991). The YSR contains the following eight syndrome scales: anxious/depressed, withdrawn/depressed, somatic complaints, social problems, thought problems, attention problems, delinquent behavior and aggressive behavior. The syndrome scales are grouped into the following subscales: 'internalizing behavioral problems', 'externalizing behavioral problems' and 'total behavioral problems'. The 'internalizing behavioral problems' scale comprises the sum of the scores of the anxious/depressed, withdrawn/depressed and somatic complaints scales. The 'externalizing behavioral problems' scale comprises the sum of the scores of the delinquent (i.e., rule-breaking behavior) and aggressive behavior scales. Social, thought and attention problems scales are not part of either internalizing or externalizing scales. Adolescents rated themselves at the age of 16 for how true each item was for them within the past six months. The response scale was not true (score 0), somewhat or sometimes true (score 1) and very true or often true (score 2). The YSR item scores were added up to obtain a summary score for each subscale. If there was one missing item in a syndrome scale, the missing item was imputed with the mean item score for that individual for the scale in question. Individuals who answered insufficiently to YSR (i.e., with more than one missing item) or who did not participate in the study were excluded $(n=2178)$. The reliability of YSR in NFBC1986 was good to excellent as per Cronbach's alpha values $(0.93,0.87$ and 0.87 for total, internalizing and externalizing scales, respectively).

\section{Parental Illness}

Information on parental illnesses was collected from the Care Register for Health Care (CRHC), which included all specialized inpatient care visits from 1994 to 2002 and outpatient visits from 1998 to 2002 in public hospitals. As such, information on parental illness diagnoses was available for the period when children were between 8 and 16 
years of age. Parental illnesses were subsumed in 16 different main diagnosis categories (codes A-E, G-Z) according to the ICD $10^{\text {th }}$ Revision (WHO, 1992). Each entity of diagnosis category forms a homogenous collection of diagnoses. As described below, parental mental and behavioral (i.e., psychiatric) diagnoses ( $F$ codes) during the study period (1994-2002) were grouped and used as a covariate in analyses. We excluded diagnostic categories that were not considered physical illnesses (Diseases of the eye and adnexa ICD9: 360-389, ICD10: H00-H59, Pregnancy, childbirth and the puerperium ICD9: 630-679, ICD10: O00-O99, ICD10: Q00-Q99, Certain conditions originating in the perinatal period ICD9:760-779, ICD10: P00-P96, Congenital malformations, deformations and chromosomal abnormalities ICD9: 740- 759). The quality of data from the CRHC has been shown to be satisfactory for statistical and research purposes (Sund, 2012).

\section{Covariates}

Covariates were selected on the basis of existing literature. Socioeconomic status (SES) of the family available during pregnancy (Amone-P'Olak et al., 2009; Najman et al., 2010), Rutter-B at the age of eight and parental psychiatric diagnoses during the study period from 1994 to 2002 (Barnes \& Stein, 2000; Gladstone et al., 2011; Thorup et al., 2018) were included as covariates. This was done to rule out that any associations were driven by broader contextual factors, children's existing behavioral problems, or comorbid parental mental health problems. SES was based on parental occupation, and was assessed by questionnaire during pregnancy. SES was classified to four categories: professionals (including entrepreneurs, 20.6\%), skilled workers $(25.6 \%)$, unskilled workers (students, pensioner, unemployed, other, $47.3 \%)$ and farmers (6.4\%). All analyses were run separately in female and male cohort members to obtain gender-specific outcomes.

\section{Statistical Methods}

We compared YSR total, externalizing, and internalizing mean scores of the offspring with and without maternal and paternal diagnosis for each illness category. The comparison group consisted of all other cohort members without the parental diagnosis category in question. As the data was normally distributed, an independent samples $t$ test was used to investigate group differences. We then used analysis of variance to evaluate group difference in YSR mean scores, adjusting for potential confounding factors. First, we adjusted for the Rutter-B score at the age of eight. Second, we ran models adjusting for other confounding variables including parental psychiatric diagnoses during the study period (from 1994 to 2002) and SES.
We used standardized mean difference as an effect size measure (Cohen's $d$ ) when comparing YSR mean scores between children with and without each separate parental disease category. Cohen's $d$ values of $\pm 0.20, \pm 0.50$ and \pm 0.80 indicate small, medium and large effects, respectively (Cohen, 1992). A negative Cohen's $d$ indicates that the YSR mean score is smaller (i.e., less behavioral problems) in the group with parental illness. Respectively, a positive Cohen's $d$ indicates higher YSR mean scores (i.e., more behavioral problems) in the group with parental illness. Two-tailed $p$ values were calculated throughout and $p<0.05$ indicated statistical significance. Further, $p$-values were corrected for multiple comparisons (16 diagnostic groups tested) using the Benjamini-Hochberg (B-H) false discovery rate procedure. We also report uncorrected results for completeness. IBM SPSS Statistics version 23 was used for data analysis.

\section{Results}

\section{Overall}

The prevalence of at least one parental physical illness diagnosis was $55.2 \%(n=3887)$ during the study period from 1994 to 2002. The two most common parental physical illness categories were diseases of the circulatory system $(22.9 \% ; n=1608)$ and diseases of the musculoskeletal system and connective tissues $(16.3 \% ; n=1150)$. The prevalence for each parental diagnosis is shown in Supplemental Table 1.

There were several significant associations between parental physical illness and children's behavioral problems. In general, the effect sizes ranged from small to moderate; Cohen's $d(d)$ ranging from -0.36 to +0.42 . All statistically significant associations are presented by gender in Table 2 and Table 3. All results are shown in Supplemental Tables 2, 3, 4 and 5 .

\section{Maternal Illness and Male Offspring}

There were several associations between maternal illness and YSR scores of male offspring (see Table 2). Male offspring with maternal diagnoses of endocrine, nutritional and metabolic diseases, $t(36.609)=2.991, p=0.005, d=$ -0.35 ; diseases of the respiratory system, $t(146.939)=$ 2.722, $p=0.007, d=-0.17$; as well as external causes of morbidity and mortality, $t(69.901)=3.216, p=0.002, d=$ -0.27 , had lower YSR total scores than male offspring without the maternal illness in question. These associations remained statistically significant after adjusting for all covariates and after B-H correction.

Maternal diagnoses of endocrine, nutritional and metabolic diseases, $t(3357)=2.088, p=0.037, d=-0.36$ and 


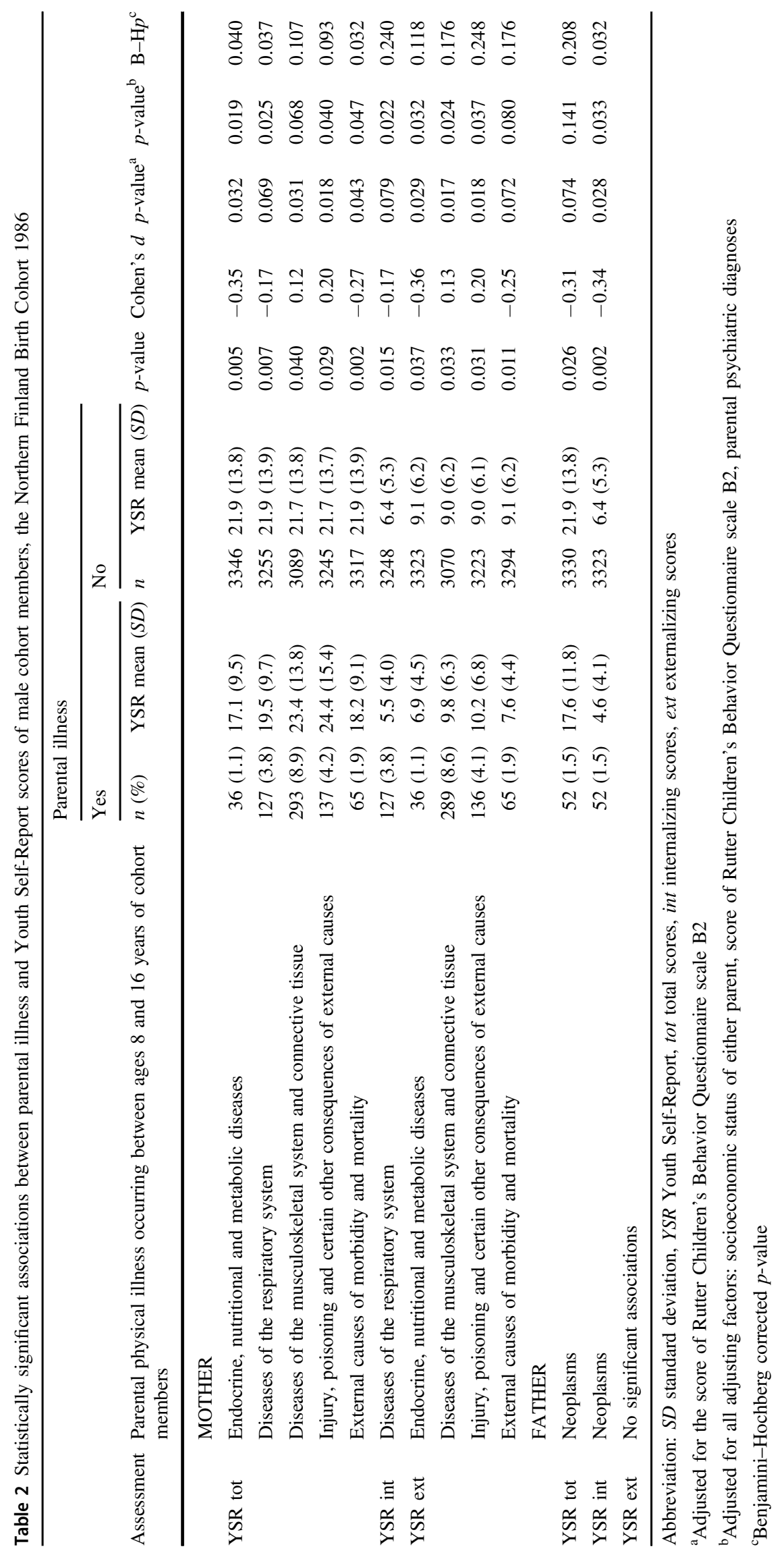


external causes of morbidity and mortality, $t(69.006)=$ 2.601, $p=0.011, d=-0.25$, were associated with lower externalizing scores of male offspring. The association of maternal diagnoses of endocrine, nutritional and metabolic diseases (but not external causes of morbidity and mortality) remained after adjusting for all covariates, but not after B-H correction. Only maternal diseases of the respiratory system, $t(144.223)=2.459, p=0.015, d=-0.17$ were associated with (lower) internalizing scores of male offspring, however, this association did not remain after $\mathrm{B}-\mathrm{H}$ correction.

In contrast, male offspring with maternal diagnoses of diseases of the musculoskeletal system and connective tissue, $t(3380)=-2.057, p=0.040, d=0.12$ and injury, poisoning and certain other consequences of external causes, $t(3380)=-2.190, p=0.029, d=0.20$, had higher YSR total scores than male offspring without the maternal illness in question. The associations did not remain after B-H correction. Maternal diseases of the musculoskeletal system and connective tissue, $t(3357)=-2.132, p=0.033$, $d=0.13$, and injury, poisoning and certain other consequences of external causes, $t(3357)=-2.152, p=0.031$, $d=0.20$ were associated with higher externalizing scores. All of the associations remained after adjusting for Rutter-B score and all other covariates, but did not survive B-H correction.

\section{Paternal Illness and Male Offspring}

In general, paternal physical illnesses were not strongly associated with male offspring's YSR scores (see Table 2 and Supplemental Table 3). There was a significant negative association between paternal neoplasm and YSR internalizing scores of male offspring, $t(53.743)=3.186, p=$ $0.002, d=-0.34$, which remained significant after the addition of covariates and $\mathrm{B}-\mathrm{H}$ correction. A negative association was found between paternal diagnoses of neoplasm and male offspring's YSR total scores, $t(3380)=$ 2.230, $p=0.026, d=-0.31$. However, the association became nonsignificant after adjusting for covariates.

\section{Maternal Illness and Female Offspring}

There were various associations between maternal illness and YSR internalizing scores of female offspring (see Table 3). Maternal diagnosis of endocrine, nutritional and metabolic diseases, $t(3650)=-2.045, p=0.041, d=0.34$, diseases of the digestive system, $t(3650)=-2.369, p=0.018$, $d=0.16$, and injury, poisoning and certain other consequences of external causes, $t(182.651)=-2.015, p=$ $0.045, d=0.18$, were associated with higher YSR internalizing scores of female offspring. Maternal diagnoses of injury, poisoning and certain other consequences of external 
causes were associated with higher YSR total scores of female offspring, $t(180.674)=-2.157, p=0.032, d=$ 0.20 . These associations remained after adjusting for the Rutter-B score and all other covariates, but did not survive $\mathrm{B}-\mathrm{H}$ correction. There were no significant findings between maternal physical illnesses and YSR externalizing scores of female offspring.

\section{Paternal IIIness and Female Offspring}

In general, paternal physical illnesses were not associated with female offspring's YSR scores (see Supplemental Table 5). There were no significant findings for the YSR total, neither externalizing nor internalizing scores.

\section{Additional Analyses}

Attrition analyses showed differences between cohort members who remained in the study until the YSR (age 16) and those who dropped out. Male children, lower SES, and urban (versus rural) families were overrepresented in those who dropped out. Children with higher Rutter-B scores, and younger mothers and fathers were also overrepresented in those who dropped out. However, additional adjustment with residency (urban, rural) and mother's and father's age at child's birth did not change the results (data not shown). To address the issue with attrition, we performed sensitivity analyses by weighting the data with information on RutterB (scores high $\geq 9$, low $<9$, no participation) and SES (upper or lower). This weighting procedure did not change the overall pattern of findings. Supplemental Tables 6 and 7 present statistically significant associations by gender after weighting the data. A few new associations became significant after weigthing procedure (but did not survive $\mathrm{B}-\mathrm{H}$ correction); an association between paternal diagnosis of external causes of morbidity and mortality and lower YSR internalizing scores among male offspring, an association between paternal diagnosis of certain infectious and parasitic diseases and lower YSR total scores among female offspring, an association between maternal diagnosis of circulatory system and lower YSR externalizing scores among female offspring and an association between maternal diagnosis of injury, poisoning and certain other consequences of external causes and higher YSR externalizing scores among female offspring. In addition, the association between maternal diagnosis of endocrine, nutritional and metabolic diseases and lower YSR externalizing scores among male offspring and the association between paternal diagnosis of neoplasms and lower YSR total scores among male offspring became nonsignificant.

Given the relatively low rates in some parental physical illness groups, comorbidity, and potential similarity in the effects of certain illnesses, we also compared each parental physical illness group against a group without any parental physical illnesses. The overall results remained the same, except for an association between paternal diagnosis of external causes of morbidity and mortality and lower YSR internalizing scores $(M=3.9$ vs. $M=6.3), t(8.516)=$ 2.858, $p=0.020, d=-0.48$ among male offspring, which became significant $(p<0.05)$, however the sample size was very low $(n=9)$ and it did not survive B-H correction $(p=$ $0.16)$. In addition, the association between maternal diagnosis of endocrine, nutritional and metabolic diseases and YSR externalizing scores among male offspring became nonsignificant.

\section{Discussion}

Our results showed that over half of the children $(55.2 \%)$ had a parent with at least one physical illness diagnosis set in specialized healthcare from the age of 8-16 (study period 1994-2002). The fact that parental physical illnesses are present for a notable proportion of children underlines its potential significance as a risk factor for behavioral problems.

Regarding the association between parental illnesses and adolescent's externalizing, internalizing and total behavioral problems (see Supplemental Table 8 for the summary of the results), in general, our findings confirm the complexity of the association between parental physical illnesses and children's behavioral problems (Chen, 2017). The hypothesis that adolescents with parental physical illness would have more behavioral problems was not fully supported. The most robust finding (i.e., remained after correction for multiple comparisons) was a negative association between parental physical illnesses and male children's behavioral problems, such that lower total and internalizing behavioral problems were seen among male cohort members with some of the parental physical illnesses. This association was not explained by existing child behavioral problems, or by parental psychiatric illness. Interestingly, male children displayed less total behavioral problem scores when a mother had a diagnosis of 'endocrine, nutritional and metabolic diseases', 'diseases of the respiratory system' or 'external causes of morbidity and mortality'. Furthermore, if a father had a diagnosis of neoplasms, male cohort members scored lower internalizing problems.

Although unexpected, lower behavioral problems in boys with an ill parent is consistent with some other research (e.g., Hoke, 2001; Visser et al., 2007). One explanation for this unexpected finding could be that male children exposed to parental illness exhibit certain positive emotions and other psychosocial benefits that increase resilience, i.e., the ability to cope with hardships. Boys may experience hope and optimism, positive emotions that have been shown to 
buffer people against negative mental health outcomes like depression (Fredrickson et al., 2003). It is known that adolescents report psychosocial benefits following a traumatic experience (Milam et al., 2004). For boys, parental illness may be a challenge that leads to personal growth and from which they may learn more about themselves and their abilities. Resilience is shaped partly by an individual's characteristics including genetics, temperament and personality, and partly by environmental factors including family, community and society (Beardslee \& Podorefsky, 1988; Davis et al., 2009; Feder et al., 2009; Friborg et al., 2005; Luthar et al., 2000; Rutter, 1985). Given the wide range of resilience factors (e.g., relationships, friends, siblings, school; Dirks et al., 2015) and the impossibility to investigate these with this study design, future research is needed to investigate the specific factors contributing to reduced behavioral problems in male adolescents exposed to parental illness. Importantly, while our findings indicate that parental physical illness is associated with fewer behavioral problems in boys, lower scores do not necessarily indicate that children feel 'better'. In contrast, lower behavioral problems can be due to suppressed feelings and emotions. Due to the exploratory nature of our study, further research is needed to confirm our preliminary findings.

Altogether, the mixed findings draw attention to potential factors, such as age, gender and parental illness characteristics, which may explain associations between parental physical illness and child behavioral problems (Grant et al., 2006). As to the hypothesized gender-specific effects, the results reveal a mixed picture. Most of the associations found were for male children, which was not in line with hypotheses (although, as discussed above, results were not in the expected direction). However, consistent with hypotheses, affected girls showed the expected higher total and internalizing symptom scores when a mother was ill (although none of these associations remained after correction for multiple comparison). This is consistent with previous studies that have suggested that girls are more vulnerable to psychological distress following parental illness (Compas et al., 1994; Sieh et al., 2012). Regarding the general finding that girls in the general population display more internalizing behavior and less externalizing behavior than boys (Boyd et al., 2015; Verhulst et al., 2003; Wagner et al., 2017), our results confirm that in children with parental physical illness, gender differences are as prominent.

Similarly, the gender of an ill parent may influence the effect of parental illnesses on children. The associations found in our study were mostly between maternal illness and children's behavioral problems. However, the hypothesis that adolescent girls show more behavioral problems when the mother is ill could not be thoroughly confirmed since the findings did not remain after correction for multiple comparisons. Nonetheless, according to our study and previous ones, the impact of parental illness on children seem to be greater for those with affected mothers than fathers (Compas et al., 1994; Connell \& Goodman, 2002; Sieh et al., 2012). In our study, there were no significant associations between paternal physical illness and female children's behavioral problems. Further, only paternal diagnoses of neoplasms and male cohort members' behavioral problems showed a statistically significant association. Fewer previous studies have focused on paternal illness.

The characteristics of the parental physical illness may influence the effect of parental illness on children. Some particular types of parental physical illnesses were emphasized in association with child behavioral problems. Firstly, the association of maternal illnesses of 'endocrine, nutritional and metabolic diseases' on lower child behavioral problems may indicate that illnesses causing a long-term stressful situation without a traumatic sudden onset of illness may impact 'positively' on children. This diagnostic group includes chronic illnesses such as diabetes, hormone dysfunction and obesity. Children may have the opportunity to learn to cope with parental chronic illness, and thus not be vulnerable to developing behavioral problems. Secondly, maternal diseases of the respiratory system were associated with lower behavioral problems in male children. This diagnostic groups includes chronic illnesses such as asthma, and the findings could be explained as above. Thirdly, maternal external causes of morbidity and mortality were associated with lower rates of behavioral problems in male children. The diagnoses in this group are merely causes of injury, poisoning and other adverse effects rather than illness diagnoses. On the whole, the onset (acute, chronic), course (duration, progressive, episodic, stable) and severity (extent of mortality threat, predictability) of the illness may vary and affect families and children in different ways. In addition, recurring separation from a parent because of hospitalizations may have more of an impact on children (Astrup et al., 2017). All of these factors require further study.

The age of a child might be a moderating factor of the relationship between parental illness and children's behavioral problems (Barkmann et al., 2007; Sieh et al., 2010; Visser et al., 2005). Although previous research has suggested that adolescents are particularly vulnerable to the negative effects of parental illness (Grant \& Compas, 1995) (potentially because they are more likely than children to take a carer role, which may be distressing), adolescents are likely able to understand parental illness and the illness process, hence they may better cope with parental illness than younger children. In our study, behavioral problems were measured in adolescence (age 16) and as such, parental illness may not have influenced behavioral problems to the same extent that they might have in younger age groups. However, further work investigating child age as a moderating factor is needed to test this hypothesis.

Family-related factors may partially explain the association between parental illness and child problem behavior. Parental 
illness has an impact on the family as a whole: parental illness does not only affect the individuals within the family, but also their relationships with one another. Furthermore, the way that families respond to adverse events varies. A study of parental cancer documented that child problems can be more a function of how families cope with stress rather than the existence of parental illness itself (Watson et al., 2006). Positive family functioning can protect children from the effects of parental physical illness. A range of factors such as family environment, education, family belief systems, social networks, and parenting style influence the way children cope with parental illness. All of these determine a family resilience process that promotes normal development and mental health (Patterson, 2002; Walsh, 2003) and help children cope with parental illness (Pakenham \& Cox, 2018). Future research should investigate these factors in order to shed light on the meaning of our results.

\section{Study Limitations}

Our study has several limitations. Although a large population sample was used, it is not representative of all nationalities. The sample is homogeneous in that it mainly consists of Caucasians living in Northern Finland and hence, the results are generalizable to Caucasians in Western countries with similar morbidity and health care. However, an homogenous population sample is also a strength in that certain confounds (e.g., ethnicity) do not impact results. The study sample represents a specific cohort (offspring born in 1985-1986) and as such findings may not be fully generalizable to contemporary populations. There are limitations in using a single assessment for offspring's behavioral problems with different informants; Rutter-B and YSR were filled out at one time point only, Rutter-B by teachers, and YSR by adolescents themselves. A large number of potential confounding variables could not be taken into account due to restrictions on data, such as information on siblings, separation from a parent and duration of parental illness, and restrictions on unmeasurable variables such as resilience. Further, genetic or other biological mechanismis may explain part of the associations. However, mediation or moderation analyses were not conducted. Future studies should focus on the factors that may moderate and mediate associations. Multiple statistical comparisons were performed which increases the possibility of chance findings, however, in order to control that, the B-H-correction for multiple comparisons was performed. Associations may be missed because of a lack of power in those parental physical illness groups having a small number of cases. We controlled for parental psychiatric diagnoses, however, parental depressive and other psychiatric symptoms can be elevated with an ill parent without a psychiatric diagnosis. A final potential limitation is that the register information on parental physical and psychiatric diagnoses includes outpatient data only from
1998 onwards (cf. study period 1994-2002) as the outpatient data was not available before this. While the inpatient data covers the complete study period, it refers to specialized care requiring hospitalization. Further, the information on primary, nonspecialized, care diagnoses is missing. Register data lacks information on private health care, however, the private health care sector is minimal and health care is mainly public in Finland. Therefore, the results are reliable, although further studies are required in order to better understand the significance of the results.

\section{Study Strengths}

Our study contributes to the literature by examining the impact of parental illness on children's behavioral problems over time. The strength of the study is the prospective large population-based sample. The sample comes from the general population and has not been selected. The study period is long and the timing of the parental illness was taken into account. The Rutter-B at the age of eight was used to adjust for baseline problems before parental physical illness, which has not been possible in previous studies on this topic. Controlling for prior problems allows for a stronger test of directionality of associations, and to our knowledge, this is the first study to control for child problems before parental illness. Many previously unknown associations were found in the model that took account prior problems before parental illness. In comparison to parental reports, adolescents' self-reported symptoms at age 16 make this study more reliable since parents may be unaware of the children's distress because of parental illness. Parental psychiatric diagnoses were taken into account since it is known that parental mental disorders are associated with an increased risk in mental health problems in children (Dean et al., 2018; Gladstone et al., 2011; Thorup et al., 2018).

\section{Practical Implications of Study Findings}

The findings have clinical and public health relevance, as physical illnesses are common medical problems with majority of parenting age adults affected. The findings highlight the importance of identifying patients with children and providing effective support for children whose parent has been diagnosed with a physical illness, whether the support is to reduce negative effects, i.e., mental health problems, or to improve positive effects, i.e., resilience. Either may potentially reduce a child's risk of future mental health problems. Health care professionals may have an important role in offering advice and information to the affected patient and to others affected by the illness, including children. Conversely, parental health status should be considered when evaluating and treating children's mental health problems. More research is needed to better understand the mechanisms of how parental physical illness affects offspring's mental health, 
particularly, to identify the risk factors associated with the negative consequences of parental illness.

\section{Conclusion}

Parental physical illnesses are common and they have a noteworthy effect on children. The findings have clinical and public health relevance as physical illnesses are common medical problems with over a half of the parenting age adults affected during 8-year period. However, the impact of parental illness on children's behavioral problems is a complex issue. Our results suggest that the experience of parental illness, especially maternal illness, may lead to resilience in males. Yet, the typology of parental illness seems to influence the associations. This study contributes to a better understanding of which parental physical illnesses are associated with later behavioral problems in adolescents. Despite the mixed findings, when viewed alongside with previous research (Sieh et al., 2010), our study emphasizes that children's needs should be taken into account when treating a parent with physical illness. More research is needed to better understand the complex interface between the child, parental illness and other factors associated with children's psychological outcomes.

\section{Data availability}

NFBC1986 data is available from the University of Oulu, Infrastructure for Population Studies. Permission to use the data can be applied for research purposes via electronic material request portal. In the use of data, NFBC1986 follows the EU general data protection regulation (679/2016) and Finnish Data Protection Act. Please, contact NFBC project center (NFBCprojectcenter@oulu.fi) and visit the cohort website (www.oulu.fi/nfbc) for more information.

Acknowledgements We thank all cohort members and researchers who have participated in the study. We also wish acknowledge the work of the NFBC project center. We thank Melbourne Neuropsychiatry Centre and the University of Melbourne for the collaboration. We also thank Dr Sanna Huhtaniska for her constructive and valuable comments.

Author Contributions All authors contributed to the study conception. L.K., J.M., S.R., M.N., and T.N. contributed to the study design. Data analysis were performed by L.K. and T.N.. The first draft of the manuscript was written by L.K., M.N., and S.W.. All authors edited and commented on previous versions of the manuscript. All authors read, provided critical review, edited and approved the final manuscript.

Funding The NFBC study is funded by EU QLG1-CT-2000-01643 (EUROBLCS) (grant number E51560), NorFA (grant number 731, 20056, 30167), USA / NIH 2000 G DF682 (grant number 50945). This study was supported by the Academy of Finland (J.M., grant numbers 268336, 288960); Finnish Cultural Foundation (L.K., grant number 00160427); Juho Vainio Foundation (L.K., grant number
201610329): The University of Oulu Scholarship Foundation (L.K., grant number 20180212), Olvi-Säätiö (L.K.), Niilo Helanderin Säätiö (L.K.) and Lastentautien tutkimussäätiö (L.K.) and the National Health and Medical Research Foundation (S.W., grant number 1007716). Open access funding provided by University of Oulu including Oulu University Hospital.

\section{Compliance with Ethical Standards}

Conflict of Interest The authors declare no competing interests.

Ethical Approval The NFBC1986 study obtained the ethics approval of the Ethical Committee of the Northern Ostrobothnia Hospital District in Finland (17 May 2006) and permission to gather and use register data and hospital records from the Finnish Ministry of Social Affairs and Health. All procedures performed in studies involving human participants were in accordance with the ethical standards of the institutional research committee and with the 1964 Helsinki declaration and its later amendments or comparable ethical standards. This article does not contain any studies with animals performed by any of the authors. Informed consent was obtained from all individual participants included in the study. Deleted for blinded review

Publisher's note Springer Nature remains neutral with regard to jurisdictional claims in published maps and institutional affiliations.

Open Access This article is licensed under a Creative Commons Attribution 4.0 International License, which permits use, sharing, adaptation, distribution and reproduction in any medium or format, as long as you give appropriate credit to the original author(s) and the source, provide a link to the Creative Commons license, and indicate if changes were made. The images or other third party material in this article are included in the article's Creative Commons license, unless indicated otherwise in a credit line to the material. If material is not included in the article's Creative Commons license and your intended use is not permitted by statutory regulation or exceeds the permitted use, you will need to obtain permission directly from the copyright holder. To view a copy of this license, visit http://creativecommons. org/licenses/by/4.0/.

\section{References}

Achenbach, T. M. (1991). Manual of the Youth Self-Report and 1991 profile. Burlington: Department of Psychiatry, University of Vermont.

Amone-P'Olak, K., Burger, H., Ormel, J., Huisman, M., Verhulst, F. C., \& Oldehinkel, A. J. (2009). Socioeconomic position and mental health problems in pre- and early-adolescents: The TRAILS study. Social Psychiatry and Psychiatric Epidemiology, 44, 231-238. https://doi.org/10.1007/s00127-008-0424-z.

Astrup, A., Pedersen, C. B., Mok, P. L. H., Carr, M. J., \& Webb, R. T. (2017). Self-harm risk between adolescence and midlife in people who experienced separation from one or both parents during childhood. Journal of Affective Disorders, 208, 582-589. https:// doi.org/10.1016/j.jad.2016.10.023.

Barkmann, C., Romer, G., Watson, M., \& Schulte-Markwort, M. (2007). Parental physical illness as a risk for psychosocial maladjustment in children and adolescents: Epidemiological findings from a national survey in Germany. Psychosomatics, 48, 476-481. https://doi.org/10.1176/appi.psy.48.6.476.

Barnes, J., \& Stein, A. (2000). Effects of parental physical and psychiatric illness on child development. In M. G. Gelder, J. J. Lopez-Ibor \& N. C. Andreasen (Eds), New Oxford Textbook of Psychiatry (pp. 1848-1855). Oxford: Oxford University Press. 
Beardslee, W. R., \& Podorefsky, D. (1988). Resilient adolescents whose parents have serious affective and other psychiatric disorders: Importance of self-understanding and relationships. The American Journal of Psychiatry, 145, 63-69. https://doi.org/10. 1176/ajp.145.1.63.

Boyd, A., Van De Velde, S., Vilagut, G., De Graaf, R., O’Neill, S., Florescu, S., Alonso, J., \& Kovess-Masfety, V. (2015). Gender differences in mental disorders and suicidality in Europe: Results from a large cross-sectional population-based study. Journal of Affective Disorders, 173, 245-254. https://doi.org/10.1016/j.jad. 2014.11.002.

Chen, C. Y.-C. (2017). Effects of parental chronic illness on children's psychosocial and educational functioning: A literature review. Contemporary School Psychology, 21, 166-176. https://doi.org/ 10.1007/s40688-016-0109-7.

Cohen, J. (1992). A power primer. Psychological Bulletin, 112, $155-159$.

Compas, B. E., Worsham, N. L., Epping-Jordan, J. E., Grant, K. E., Mireault, G., Howell, D. C., \& Malcarne, V. L. (1994). When mom or dad has cancer: Markers of psychological distress in cancer patients, spouses, and children. Health Psychology, 13, $507-515$.

Connell, A. M., \& Goodman, S. H. (2002). The association between psychopathology in fathers versus mothers and children's internalizing and externalizing behavior problems: A meta-analysis. Psychological Bulletin, 128, 746-773. https://doi.org/10.1037// 0033-2909.128.5.746.

Davis, M. C., Luecken, L., \& Lemery-Chalfant, K. (2009). Resilience in common life: Introduction to the special issue. Journal of Personality, 77, 1637-1644. https://doi.org/10.1111/j.1467-6494. 2009.00595.x.

Dean, K., Green, M. J., Laurens, K. R., Kariuki, M., Tzoumakis, S., Sprague, T., Lenroot, R., \& Carr, V. J. (2018). The impact of parental mental illness across the full diagnostic spectrum on externalising and internalising vulnerabilities in young offspring. Psychological Medicine, 48, 2257-2263. https://doi.org/10.1017/ S0033291717003786.

De Hert, M., Correll, C. U., Bobes, J., Cetkovich-Bakmas, M., Cohen, D., Asai, I., Detraux, J., Gautam, S., Möller, H.-J., Ndetei, D. M., Newcomer, J. W., Uwakwe, R., \& Leucht, S. (2011). Physical illness in patients with severe mental disorders. I. Prevalence, impact of medications and disparities in health care. World Psychiatry: Official Journal of the World Psychiatric Association, 10, 52-77. https://doi.org/10.1002/j.20515545.2011.tb00014.x.

Dirks, M. A., Persram, R., Recchia, H. E., \& Howe, N. (2015). Sibling relationships as sources of risk and resilience in the development and maintenance of internalizing and externalizing problems during childhood and adolescence. Clinical Psychology Review, 42, 145-155. https://doi.org/10.1016/j.cpr.2015.07.003.

Feder, A., Nestler, E. J., \& Charney, D. S. (2009). Psychobiology and molecular genetics of resilience. Nature Reviews Neuroscience, 10, 446-457. https://doi.org/10.1038/nrn2649.

Fredrickson, B. L., Tugade, M. M., Waugh, C. E., \& Larkin, G. R. (2003). What good are positive emotions in crises? A prospective study of resilience and emotions following the terrorist attacks on the United States on September 11th, 2001. Journal of Personality and Social Psychology, 84, 365-376. https://doi.org/10. 1037/0022-3514.84.2.365.

Friborg, O., Barlaug, D., Martinussen, M., Rosenvinge, J. H., \& Hjemdal, O. (2005). Resilience in relation to personality and intelligence. International Journal of Methods in Psychiatric Research, 14, 29-42.

Gladstone, B. M., Boydell, K. M., Seeman, M. V., \& McKeever, P. D. (2011). Children's experiences of parental mental illness: A literature review. Early Intervention in Psychiatry, 5, 271-289. https://doi.org/10.1111/j.1751-7893.2011.00287.x.
Grabiak, B. R., Bender, C. M., \& Puskar, K. R. (2007). The impact of parental cancer on the adolescent: An analysis of the literature. Psycho-Oncology, 16, 127-137. https://doi.org/10.1002/pon. 1083.

Grant, K. E., \& Compas, B. E. (1995). Stress and anxious-depressed symptoms among adolescents: Searching for mechanisms of risk. Journal of Consulting and Clinical Psychology, 63, 1015-1021.

Grant, K. E., Compas, B. E., Thurm, A. E., McMahon, S. D., Gipson, P. Y., Campbell, A. J., Krochock, K., \& Westerholm, R. I. (2006). Stressors and child and adolescent psychopathology: Evidence of moderating and mediating effects. Clinical Psychology Review, 26(3), 257-283. https://doi.org/10.1016/j.cpr. 2005.06.011.

Hoke, L. A. (2001). Psychosocial adjustment in children of mothers with breast cancer. Psycho-Oncology, 10, 361-369. https://doi. org/10.1002/pon.515.

Houck, C. D., Rodrigue, J. R., \& Lobato, D. (2007). Parent - adolescent communication and psychological symptoms among adolescents with chronically ill parents. Journal of Pediatric Psychology, 32, 596-604. https://doi.org/10.1093/jpepsy/js1048.

Jantzer, V., Groß, J., Stute, F., Parzer, P., Brunner, R., Willig, K., Schuller-Roma, B., Keller, M., Herzog, W., Romer, G., \& Resch, F. (2013). Risk behaviors and externalizing behaviors in adolescents dealing with parental cancer-a controlled longitudinal study. Psycho-Oncology, 22, 2611-2616. https://doi.org/10.1002/ pon.3327.

Korneluk, Y. G., \& Lee, C. M. (1998). Children's adjustment to parental physical illness. Clinical Child and Family Psychology Review, 1, 179-193.

Krattenmacher, T., Kühne, F., Ernst, J., Bergelt, C., Romer, G., \& Möller, B. (2012). Parental cancer: Factors associated with children's psychosocial adjustment - a systematic review. Journal of Psychosomatic Research, 72(5), 344-356. https://doi.org/10. 1016/j.jpsychores.2012.01.011.

Kresanov, K., Tuominen, J., Piha, J., \& Almqvist, F. (1998). Validity of child psychiatric screening methods. European Child and Adolescent Psychiatry, 7, 85-95.

Lindqvist, B., Schmitt, F., Santalahti, P., Romer, G., \& Piha, J. (2007). Factors associated with the mental health of adolescents when a parent has cancer. Scandinavian Journal of Psychology, 48, 345-351. https://doi.org/10.1111/j.1467-9450.2007.00573.x.

Luthar, S. S., Cicchetti, D., \& Becker, B. (2000). The construct of resilience: A critical evaluation and guidelines for future work. Child Development, 71, 543-562.

Merikukka, M., Räsänen, S., Hakko, H., Ristikari, T., Gissler, M., \& Niemelä, M. (2020). Association between parental hospitaltreated somatic illnesses in childhood and later mental disorders among offspring up to early adulthood: An explorative study in the 1987 Finnish Birth Cohort. Scandinavian Journal of Public Health, 48, 214-223.

Miettunen, J., Haapea, M., Björnholm, L., Huhtaniska, S., Juola, T., Kinnunen, L., Lehtiniemi, H., Lieslehto, J., Rautio, N., \& Nordström, T. (2019). Psychiatric research in the Northern Finland Birth Cohort 1986 - A systematic review. International Journal of Circumpolar Health, 78(1), 1571382 https://doi.org/ 10.1080/22423982.2019.1571382.

Milam, J. E., Ritt-Olson, A., \& Unger, J. B. (2004). Posttraumatic growth among adolescents. Journal of Adolescent Research, 19, 192-204. https://doi.org/10.1177/0743558403258273.

Möller, B., Barkmann, C., Krattenmacher, T., Kühne, F., Bergelt, C., Beierlein, V., Ernst, J., Brähler, E., Flechtner, H. H., Herzog, W., Von Klitzing, K., Führer, D., Resch, F., \& Romer, G. (2014). Children of cancer patients: Prevalence and predictors of emotional and behavioral problems. Cancer, 120, 2361-2370.

Najman, J. M., Hayatbakhsh, M. R., Clavarino, A., Bor, W., O'Callaghan, M. J., \& Williams, G. M. (2010). Family poverty over the early life 
course and recurrent adolescent and young adult anxiety and depression: A longitudinal study. American Journal of Public Health, 100, 1719-1723. https://doi.org/10.2105/AJPH.2009.180943.

Nolen-Hoeksema, S., \& Davis, C. (2002). Positive responses to loss: Perceiving benefits and growth. In C. R. Snyder \& S. J. Lopez (Eds), Handbook of positive psychology (pp. 598-606). New York, NY: Oxford University Press.

Osborn, T. (2007). The psychosocial impact of parental cancer on children and adolescents: A systematic review. Psycho-Oncology, 16, 101-126. https://doi.org/10.1002/pon.1113.

Pakenham, K. I., \& Cox, S. (2018). Effects of benefit finding, social support and caregiving on youth adjustment in a parental illness context. Journal of Child and Family Studies, 27, 2491-2506. https://doi.org/10.1007/s10826-018-1088-2.

Patterson, J. M. (2002). Understanding family resilience. Journal of Clinical Psychology, 58, 233-246.

Pedersen, S., \& Revenson, T. A. (2005). Parental illness, family functioning, and adolescent well-being: a family ecology framework to guide research. Journal of Family Psychology, 19, 404-419. https://doi.org/10.1037/0893-3200.19.3.404.

Razaz, N., Joseph, K. S., Boyce, W. T., Guhn, M., Forer, B., Carruthers, R., Marrie, R. A., \& Tremlett, H. (2016). Children of chronically ill parents: relationship between parental multiple sclerosis and childhood developmental health. Multiple Sclerosis, 22, 1452-1462. https://doi.org/10.1177/1352458515621624.

Rutter, M. (1967). A children's behaviour questionnaire for completion by teachers: preliminary findings. Journal of Child Psychology and Psychiatry, and Allied Disciplines, 8, 1-11.

Rutter, M. (1985). Resilience in the face of adversity: protective factors and resistance to psychiatric disorder. The British Journal of Psychiatry, 147, 598-611.

Sieh, D. S., Meijer, A. M., Oort, F. J., Visser-Meily, J. M. A., \& van der Leij, D. A. V. (2010). Problem behavior in children of chronically ill parents: a meta-analysis. Clinical Child and Family Psychology Review, 13, 384-397. https://doi.org/10.1007/s10567-010-0074-z.

Sieh, D. S., Visser-Meily, J. M. A., Oort, F. J., \& Meijer, A. M. (2012). Risk factors for problem behavior in adolescents of parents with a chronic medical condition. European Child and Adolescent Psychiatry, 21, 459-471. https://doi.org/10.1007/s00787-012-0279-4.

Stoeckel, M., \& Weissbrod, C. (2015). Growing up with an ill parent: An examination of family characteristics and parental illness features. Families, Systems and Health, 33, 356-362. https://doi. org/10.1037/fsh0000140.

Stoeckel, M., Weissbrod, C., \& Ahrens, A. (2015). The adolescent response to parental illness: The influence of dispositional gratitude. Journal of Child and Family Studies, 24, 1501-1509. https://doi.org/10.1007/s10826-014-9955-y.

Sund, R. (2012). Quality of the Finnish hospital discharge register: A systematic review. Scandinavian Journal of Public Health, 40, 505-515. https://doi.org/10.1177/1403494812456637.

Thorup, A. A. E., Laursen, T. M., Munk-Olsen, T., Ranning, A., Mortensen, P. B., Plessen, K. J., \& Nordentoft, M. (2018). Incidence of child and adolescent mental disorders in children aged 0-17 with familial high risk for severe mental illness - A Danish register study. Schizophrenia Research, 197, 298-304. https://doi.org/10.1016/j.schres.2017.11.009.

Tompkins, T., \& Wyatt, G. (2008). Child psychosocial adjustment and parenting in families affected by maternal HIV/AIDS. Journal of Child and Family Studies, 17, 823-838.
Umberger, W. (2014). Children of parents with chronic noncancer pain: A comprehensive review of the literature. Journal of Child and Adolescent Psychiatric Nursing, 27, 26-34. https://doi.org/ 10.1111/jcap.12055.

Verhulst, F. C., Achenbach, T. M., van der Ende, J., Erol, N., Lambert, M. C., Leung, P. W. L., Silva, M. A., Zilber, N., \& Zubrick, S. R. (2003). Comparisons of problems reported by youths from seven countries. American Journal of Psychiatry, 160, 1479-1485. https://doi.org/10.1176/appi.ajp.160.8.1479.

Visser, A., Huizinga, G. A., Hoekstra, H. J., van der Graaf, W. T. A., Klip, E. C., Pras, E., \& Hoekstra-Weebers, J. E. H. M. (2005). Emotional and behavioural functioning of children of a parent diagnosed with cancer: A cross-informant perspective. PsychoOncology, 14, 746-758. https://doi.org/10.1002/pon.902.

Visser, A., Huizinga, G. A., Hoekstra, H. J., Van Der Graaf, W. T., Gazendam-Donofrio, S. M., \& Hoekstra-Weebers, J. E. (2007). Emotional and behavioral problems in children of parents recently diagnosed with cancer: A longitudinal study. Acta Oncologica, 46, 67-76. https://doi.org/10.1080/02841860600949560.

Vos, T., Allen, C., Arora, M., Barber, R. M., Bhutta, Z. A., Brown, A., Carter, A., Casey, D. C., Charlson, F. J., Chen, A. Z., Coggeshall, M., Cornaby, L., Dandona, L., Dicker, D. J., Dilegge, T., Erskine, H. E., Ferrari, A. J., Fitzmaurice, C., Fleming, T., \& Boufous, S. (2016). Global, regional, and national incidence, prevalence, and years lived with disability for 310 diseases and injuries, 1990-2015: A systematic analysis for the Global Burden of Disease Study 2015. The Lancet, 388, 1545-1602. https://doi.org/ 10.1016/S0140-6736(16)31678-6.

Wagner, G., Zeiler, M., Waldherr, K., Philipp, J., Truttmann, S., Dür, W., Treasure, J. L., \& Karwautz, A. F. K. K. (2017). Mental health problems in Austrian adolescents: a nationwide, two-stage epidemiological study applying DSM-5 criteria. European Child and Adolescent Psychiatry, 26, 1483-1499. https://doi.org/10. 1007/s00787-017-0999-6.

Walsh, F. (2003). Family resilience: a framework for clinical practice. Family Process, 42, 1-18.

Watson, M., St James-Roberts, I., Ashley, S., Tilney, C., Brougham, B., Edwards, L., Baldus, C., \& Romer, G. (2006). Factors associated with emotional and behavioural problems among school age children of breast cancer patients. British Journal of Cancer, 94, 43-50. https://doi.org/10.1038/sj.bjc.6602887.

Welch, A. S., Wadsworth, M. E. \& Compas, B. E. (1996). Adjustment of children and adolescents to parental cancer: parents' and children's perspectives. Cancer, 77, 1409-1418. https://doi.org/ 10.1002/(SICI)1097-0142(19960401)77:73.0.CO;2-4.

World Health Organization. (1992). The ICD-10 classification of mental and behavioral disorders: Clinical descriptions and diagnostic guidelines. Geneva, Switzerland: World Health Organization.

Worsham, N. L., Compas, B. E., \& Ey, S. (1997). Children's coping with parental illness. In S. A. Wolchik \& I. N. Sandler (Eds), Handbook of childrens coping: Linking theory and intervention (pp. 195-213). New York, NY: Plenum. https://doi.org/10.1007/ 978-1-4757-2677-0_7.

Zhao, Q., Li, X., Fang, X., Zhao, G., Zhao, J., Lin, X., \& Stanton, B. (2010). Difference in psychosocial well-being between paternal and maternal AIDS orphans in rural China. The Journal of the Association of Nurses in AIDS Care, 21, 335-344. https://doi.org/ 10.1016/j.jana.2009.12.001. 